\title{
ESTUDO COMPARATIVO ENTRE O FIO DE NAILON E A LINHA DE PESCA (POLIAMIDA) E A SUA APLICABILIDADE COMO FIO CIRÚRGICO
}

\author{
SHEILA CANEVESE RAHAL ${ }^{1}$; MANOEL ÁLVARO GUIMARÃES ${ }^{2}$; JOSÉ VICENTE FORTES ${ }^{3}$; \\ HÉLIO LANGONI ${ }^{4}$; PEDRO HELIO LUCCHIARI ${ }^{5}$
}

\author{
${ }^{1}$ Departamento de Cirurgia e Anestesiologia Veterinária - Faculdade de Medicina Veterinária e Zootecnia- \\ Unesp - Campus de Botucatu (SP). ${ }^{2}$ Cemeq - Centro de Manutenção de Equipamentos - Universidade \\ Estadual Paulista - Campus de Botucatu (SP). ${ }^{3}$ Cemeq - Centro de Manutenção de Equipamentos - \\ Universidade Estadual Paulista - Campus de Botucatu (SP). ${ }^{4}$ Departamento de Higiene Veterinária e Saúde \\ Pública - Faculdade de Medicina Veterinária e Zootecnia - Unesp-Campus de Botucatu (SP). ${ }^{5}$ Curso de \\ Medicina - Centro de Ciências Biológicas e da Saúde - Pontifícia Universidade Católica do Paraná.
}

\begin{abstract}
A comparative study has been carried out between fishing lines and nylon thread in regard to their applicability as surgical thread. Four groups of 10 fishing lines in each of the following diameters = $0.15,0.20,0.25$ and $0.30 \mathrm{~mm}=$ were subjected to the following treatments: group I, control; group II sterilized with formalin tablets; group III, autoclaved 30 minutes at $121^{\circ} \mathrm{C}$; group IV, autoclaved twice 30 minutes at $121^{\circ} \mathrm{C}$. The following parameters were then considered: length, caliber, resistance at the knot, and elongation. Ten samples of each surgical $0,1.0,2.0,3.0,4.0$ and 5.0 nylon threads were used in comparatively similar experiments as the ones carried out with the fishing lines. According to the statistical analyses of the experimental results, it has been found that the sterilization by means of the humid heat exerts an adverse effect on the resistance of the fishing line. However, no differences were found between the effect displayed by two cycles sterilization compared with the fishing lines subjected to only one cycle. The threads maintained in formalin kept the majority of their original properties of resistance, length, diameter and elongation when compared with the control group. It is known, however that formaldehyde is an irritant chemical towards the skin and the mucous membranes. It was possible to conclude: a. fishing lines display characteristics similar to that ones of the nylon surgical thread; b. they can be maintained in formalin solution; c. autoclave sterilization alters some of their physical properties.
\end{abstract}

RESUMO - "Linhas de pesca"* em diâmetros de 0,15mm;0,20mm;0,25mm;0,30mm foram divididas em quatro grupos, contendo dez amostras de cada diâmetro: grupo I - controle; grupo II - linhas colocadas em frasco com pastilhas de formalina; grupo III - um ciclo de autoclavagem ( 30 minutos à $121^{\circ} \mathrm{C}$, seguido por 10 minutos de secagem à $37^{\circ} \mathrm{C}$ em estufa); grupo IV - dois ciclos de autoclavagens. Foram avaliadas quanto: comprimento, calibre, resistência no nó e alongamento. Comparativamente foram examinados fios de náilon cirúrgico nas numerações $0,1-0,2-0,3-0,4-0$ e 5-0 (10 amostras de cada um). Pelos resultados da análise estastística, verificou-se que a esterilização pelo calor úmido exerceu um efeito adverso na resistência da "linha de pesca". Por outro lado não houve diferenças na resistência, calibre e alongamento da "linha de pesca" entre o primeiro e segundo ciclo de autoclavagem. As "linhas" mantidas em pastilhas de formalina mantiveram na sua maioria suas características originais de resistência, comprimento, diâmetro e alongamento quando comparada ao grupo controle, entretanto, cabe lembrar que o formaldeído é considerado irritante para pele e membrana mucosa. Foi possível concluir que a "linha de pesca" apresenta características semelhantes ao fio cirúrgico, podendo ser mantida em pastilhas de formalina ou esterilizada em autoclave, lembrando que a autoclavagem altera algumas de suas propriedades físicas.

\section{Introdução}

O desenvolvimento e o aprimoramento dos materiais de sutura têm sido notáveis, tendo oferecido ao cirurgião ampla variedade de fios absorvíveis e inabsorvíveis. As características do fio ideal, até agora não alcançada por nenhum tipo, são: grande resistência à tração e torção; calibre fino e regular; mole, flexível e pouco elástico; ausência de reação tecidual; esterilização fácil; resistente a esterilizações repetidas; custo baixo

*Linha de pesca - Grilon
(BELLEN e MAGALHÃES, 1989).

O náilon (poliamida) é um polímero de cadeia longa que se encontra disponível nas formas monofilamentar ou multifilamentar (TURNER e McILWRAITH, 1985), sendo biologicamente inerte e não capilar na forma monofilamentar (BOOTHE, 1985).

Como todo fio cirúrgico, sua numeração é expressa pelo sistema USP (Farmacopéia dos Estados Unidos) como 2-0, 3-0, etc., sendo a relação entre a numeração do fio e seu diâmetro correspondente em milímetros, bastante variável. Há um valor mínimo e máximo na dependência do 
número, como por exemplo: o no 0 varia de 0,35 $\mathrm{mm}$ até $0,40 \mathrm{~mm}$, o $\mathrm{n} \underline{\mathrm{O}} 2-0$ de $0,30 \mathrm{~mm}$ até 0,34 $\mathrm{mm}$, o no 3-0 de 0,20 $\mathrm{mm}$ até 0,25 mm; o no $4-0$ de $0,15 \mathrm{~mm}$ até $0,20 \mathrm{~mm}$ e o $\mathrm{n}$ 으 $5-0$ de $0,10 \mathrm{~mm}$ até $0,15 \mathrm{~mm}$. (BELLEN e MAGALHÃES, 1989). Normalmente, a embalagem do fabricante não traz referências quanto à resistência do fio.

Segundo BOOTHE (1985), o náilon é intermediário em força de tensão, sendo que, após a implantação, o monofilamentar perde cerca de $30 \%$ de sua força de tensão original em dois anos, enquanto que como multifilamentar quase nenhuma força é retida após seis meses.

As principais desvantagens do material são suas pobres características de manipulação e segurança do nó (BOOTHE 1985). De acordo com TURNER e McILWRAITH (1985), o náilon é uma sutura rija, devendo ser estirada para fora logo após a sua remoção do pacote do fabricante por causa da tendência a reverter à configuração original, fenômeno esse conhecido como "memória do fio". A segurança do nó, conforme BOOTHE (1985), pode ser melhorada pelo emprego cuidadoso de 4 ou 5 seminós. Entretanto, o nó tende a ser volumoso e leva tempo para ser elaborado.

Nesse contexto, CAMPBELL e MARKS (1985) relataram que o náilon não é um material caro, sendo facilmente esterilizado por autoclavagem. Pela classificação de SMEAK (1990), o náilon apresenta mínima perda de resistência com autoclavagem, podendo resistir ao processo por 3 vezes consecutivas com pouco efeito.

DUBIN e GREENBERG (1981), observando o efeito de repetidas esterilizações (30 minutos a $120^{\circ} \mathrm{C}$, seguido por 10 minutos de secagem) na resistência da sutura de poliamida sintética (Vetafil), concluíram que há cerca de $0,5 \%$ de perda por ciclo de autoclavagem. Embora a perda da resistência, após 10 a 20 ciclos de autoclavagem não impeça o uso do material de sutura, citaram que a impressão subjetiva é de que repetidas esterilizações prejudicam as propriedades físicas desse material, o número de ciclos sendo um parâmetro que deve ser levado em consideração.

BELLENGER e MEEK (1990) afirmaram que a "linha de pesca" de náilon de aproximadamente $3 \mathrm{~kg}$ de resistência, pode ser autoclavada e usada para suturas de pele de uma forma menos onerosa em comparação ao Vetafil ou Supramid.

Em geral, as "linhas de pesca" trazem informações do fabricante quanto ao seu diâmetro $(\mathrm{mm})$ e resistência $(\mathrm{kg})$ da linha sem nó. Na linha de pesca da marca Grilon encontram-se as linhas de diâmetro $0,30 \mathrm{~mm}$ com $4,5 \mathrm{~kg}$ de resistência; $0,25 \mathrm{~mm}$ com $3,5 \mathrm{~kg} ; 0,20 \mathrm{~mm}$ com $2,1 \mathrm{~kg}$ e 0,15 $\mathrm{mm}$ com $1,3 \mathrm{~kg}$.

Em função do baixo custo e da pouca reação tecidual, a "linha de pesca" (poliamida) tem também sido empregada no Brasil, por Médicos Veterinários, como material tanto para suturas de pele como para suturas internas. Como há poucas informações disponíveis publicadas sobre o uso deste material, o trabalho teve por objetivos verificar os seguintes fatos:

a. As alterações ocorridas na "linha de pesca" com relação aos métodos de esterilização a que são mais comumente submetidas, isto é, autoclavagem e pastilhas de formalina; b. As variações sofridas com relação aos ciclos de autoclavagem; c. As características físicas da "linha de pesca" em relação ao fio de náilon cirúrgico.

É importante, pois, nesse contexto, estabelecer considerações cuidadosas a respeito do número de ciclos de autoclavagem e a sua repercussão quanto à resistência deste importante material.

\section{Material e Métodos}

Linhas de pesca. Foram utilizadas "linhas de pesca" da marca Grilon nos diâmetros de $0,15 \mathrm{~mm}$; $0,20 \mathrm{~mm} ; 0,25 \mathrm{~mm} ; 0,30 \mathrm{~mm}$ em comprimentos de 1,5 metros sem sofrer estiramento e colocadas em envoltórios de papel de cartolina com as extremidades presas e o restante da linha disposta de forma ovalada no interior (simulando $o$ envoltório comercial do fio cirúrgico). Posteriormente, foram divididas em quatro grupos, contendo dez amostras de cada diâmetro, a saber: Grupo I - grupo controle; Grupo II - linhas em envoltórios colocados em frasco com pastilhas de formalina; Grupo III - cada envoltório foi colocado em envelope de celofane e autoclavado uma vez (30 minutos à $121^{\circ} \mathrm{C}$, seguido por 10 minutos de secagem à $37^{\circ} \mathrm{C}$ em estufa); Grupo IV - idem grupo III, porém submetidos a dois ciclos de autoclavagem.

As linhas foram avaliadas quanto: acomprimento (sem retirada da "memória"); bcalibre ( $\mathrm{mm}$ ); c- resistência no nó (força requerida para a ruptura da sutura ao nível do nó); dalongamento (a distância percorrida pelo sistema de tração desde o início do estiramento até a ruptura do nó).

Aparelho para medida da resistência e do alongamento dos fios. O método utilizado na medida da resistência e do alongamento dos fios foi o descrito por NARESSE et al., (1987) e posteriormente por GUIMARÃES et al., (1998), que desenvolveram um aparelho para medida da força de ruptura em processos de cicatrização. Para efetuar as medidas de resistência e alongamento, as "linhas de pesca" foram submetidas ao ensaio de tração. Aproximadamente 40

\footnotetext{
Linha de pesca - Grilon
} 
Fio de Nailon e Linha de Pesca-Poliamida como Fios Cirúrgicos

cm de linha foi amarrada ao redor de um tubo de borracha flexível $(55 \mathrm{~mm}$ de diâmetro externo por 1 $\mathrm{mm}$ de espessura de parede), por meio de um nó de cirurgião com 2 seminós, e cada uma das extremidades da linha foi presa nas garras do sistema de tração. O comprimento efetivo da linha entre as garras foi de $10 \mathrm{~cm}$, com o nó situado na metade do caminho. As linhas foram distendidas a uma velocidade constante de 7,5 centímetro por minuto até a ruptura, por meio de deslocamento uniforme da garra inferior do aparelho. Todos os nós foram realizados por uma única pessoa e apertados de uma forma moderada. Foram obtidos os valores no momento da ruptura e do alongamento resultantes da tração até a ruptura. Os valores do alongamento resultante da tração e da força de ruptura no momento em que ela ocorreu, foram anotados para posterior análise.

Micrômetro externo. A medida dos diâmetros dos fios foi feita com micrômetro marca Titutoyo do Brasil, modelo 103137.

Esterilização. Para controle dos métodos de esterilização, amostras das "linhas de pesca" foram colhidas e passadas para meio de caldo cérebrocoração (BHD-DIFCO) incubado a $37^{\circ} \mathrm{C}$ por setenta e duas horas, observando-se o crescimento bacteriano a cada 24 horas.

Analise estatística. A análise estatística utilizada na comparação dos quatro grupos experimentais (controle, formalina, autoclavado uma vez, autoclavado duas vezes), em cada um dos fios, foi feita pela técnica de Análise de Variância (BUSSAB, 1986) para experimentos inteiramente casualizados e complementada com o Teste de Comparação Múltipla de Médias de Tukey (OSTLE, 1973). Todos os testes estatísticos foram realizados considerando o nível de $5 \%$ de significância.

Esterelização com radiação gama. Foram, também, examinados fios de náilon cirúrgico (esterilizados com radiação gama) nas numerações $0,1-0,2-0,3-0,4-0$ e 5-0 (10 amostras de cada um) quanto ao calibre $(\mathrm{mm})$, resistência no nó e alongamento.

\section{Resultados}

Não foi observado crescimento bacteriano em 72 horas nas "linhas de pesca" tanto em formalina como autoclavadas.

Após a autoclavagem foi observada uma alteração da coloração da linha que de transparente tornou-se "amarelada". Também ficou mais maleável à manipulação. A memória ficou mais acentuada com a autoclavagem, do que com a formalina.

Os resultados das medidas de calibre, comprimento, resistência e alongamento das "linhas de pesca" encontram-se nas Tabelas 1, 2, 3 e 4, sendo que os valores de resistência dos grupos controles foram inferiores aos citados pelo fabricante.

Os valores de calibre, resistência e alongamento dos fios cirúrgicos encontram-se na Tabela 5.

Tabela 1. Média (x) e desvio-padrão(s) do calibre (mm) das "linha de pesca" 0,15;0,20;0,25;0,30 nos grupos I (controle), II (formalina), III (autoclavado uma vez) e IV (autoclavado duas vezes).

\begin{tabular}{lllll}
\hline GRUPOS & \multicolumn{4}{c}{ LINHAS } \\
\cline { 2 - 5 } & 0,15 & 0,20 & 0,25 & 0,30 \\
\hline I & $0,1384 \pm 0,0022^{\mathrm{a}}$ & $0,1952 \pm 0,0017^{\mathrm{a}}$ & $0,2469 \pm 0,0017^{\mathrm{a}}$ & $0,2970 \pm 0,0045^{\mathrm{a}}$ \\
II & $0,1416 \pm 0,0046^{\mathrm{a}}$ & $0,1985 \pm 0,0012^{\mathrm{b}}$ & $0,2480 \pm 0,0026^{\mathrm{a}}$ & $0,2941 \pm 0,0036^{\mathrm{a}}$ \\
III & $0,1462 \pm 0,0025^{\mathrm{b}}$ & $0,2021 \pm 0,0033^{\mathrm{c}}$ & $0,2526 \pm 0,0016^{\mathrm{b}}$ & $0,3056 \pm 0,0039^{\mathrm{b}}$ \\
IV & $0,1471 \pm 0,0013^{\mathrm{b}}$ & $0,2000 \pm 0,0008^{\mathrm{bc}}$ & $0,2531 \pm 0,0017^{\mathrm{b}}$ & $0,3078 \pm 0,0036^{\mathrm{b}}$ \\
\hline DMS (5\%) & 0,0035 & 0,0024 & 0,0023 & 0,0048
\end{tabular}

DMS : Diferença mínima significativa.

De maneira geral, em quase todos os calibres e comprimentos foi possível mostrar diferenças significativas entre os grupos III e IV entre si e com os grupos I e II.

Em quase todas as medidas de resistência foi possível demonstrar diferenças significativas entre os grupos III e IV com os grupos I e II. Os grupos I e II não diferiram entre si, tendo resultados maiores que os dos grupos III e IV. $(\mathrm{GI}=\mathrm{GII})>(\mathrm{GIII}=\mathrm{GIV})$. 
Tabela 2. Média (x) e desvio- padrão (s) do comprimento (m) das "linhas de pesca" 0,$15 ; 0,20 ; 0,25 ; 0,30$ nos grupos I (controle), II (formalina), III (autoclavado uma vez) e IV ( autoclavado duas vezes).

\begin{tabular}{lllll}
\hline GRUPOS & \multicolumn{4}{c}{ LINHAS } \\
\cline { 2 - 5 } & 0,15 & 0,20 & 0,25 & 0,30 \\
\hline I & $1,500 \pm 0^{\mathrm{a}}$ & $1,500 \pm 0^{\mathrm{a}}$ & $1,500 \pm 0^{\mathrm{a}}$ & $1,500 \pm 0^{\mathrm{a}}$ \\
II & $1,500 \pm 0^{\mathrm{a}}$ & $1,500 \pm 0^{\mathrm{a}}$ & $1,500 \pm 0^{\mathrm{a}}$ & $1,500 \pm 0^{\mathrm{a}}$ \\
III & $1,355 \pm 0,006^{\mathrm{b}}$ & $1,344 \pm 0,008^{\mathrm{b}}$ & $1,307 \pm 0,016^{\mathrm{b}}$ & $1,338 \pm 0,031^{\mathrm{b}}$ \\
IV & $1,309 \pm 0,017^{\mathrm{c}}$ & $1,315 \pm 0,012^{\mathrm{c}}$ & $1,286 \pm 0,016^{\mathrm{c}}$ & $1,310 \pm 0,042^{\mathrm{b}}$ \\
\hline DMS (5\%) & 0.011 & 0,0086 & 0,013 & 0,032 \\
\hline
\end{tabular}

DMS : Diferença mínima significativa.

Tabela 3. Médias (x) e desvio-padrão (s) da resistência (kg) das "linhas de pesca" 0,$15 ; 0,20 ; 0,25 ; 0,30$ nos grupos I (controle), II (formalina), III (autoclavado uma vez) e IV (autoclavado duas vezes).

\begin{tabular}{|c|c|c|c|c|}
\hline \multirow[t]{2}{*}{ GRUPOS } & \multicolumn{4}{|c|}{ LINHAS } \\
\hline & 0,15 & 0,20 & 0,25 & 0,30 \\
\hline $\mathrm{I}$ & $1,08 \pm 0,09^{\mathrm{a}}$ & $1,73 \pm 0,15^{\mathrm{a}}$ & $2,50 \pm 0,12^{\mathrm{a}}$ & $3,36 \pm 0,22^{\mathrm{a}}$ \\
\hline II & $1,08 \pm 0,10^{\mathrm{a}}$ & $1,83 \pm 0,13^{a}$ & $2,54 \pm 0,12^{\mathrm{a}}$ & $3,34 \pm 0,27^{\mathrm{a}}$ \\
\hline III & $1,03 \pm 0,04^{\mathrm{ab}}$ & $1,54 \pm 0,11^{b}$ & $2,30 \pm 0,09^{b}$ & $3,05 \pm 0,15^{\mathrm{b}}$ \\
\hline IV & $0,96 \pm 0,07^{\mathrm{b}}$ & $1,41 \pm 0,09^{b}$ & $2,18 \pm 0,08^{b}$ & $3,01 \pm 0,12^{\mathrm{b}}$ \\
\hline DMS (5\%) & 0,10 & 0.15 & 0,13 & 0,24 \\
\hline
\end{tabular}

Tabela 4. Médias (x) e desvio-padrão (s) do alongamento $(\mathrm{cm})$ das "linhas de pesca" 0,$15 ; 0,20 ; 0,25 ; 0,30$ nos grupos I (controle), II (formalina), III (autoclavado uma vez) e IV (autoclavado duas vezes).

\begin{tabular}{lllll}
\hline GRUPOS & \multicolumn{4}{c}{ LINHAS } \\
\cline { 2 - 5 } & 0,15 & 0,20 & 0,25 & 0,30 \\
\hline I & $2,87 \pm 0,22^{\mathrm{a}}$ & $3,10 \pm 0,24^{\mathrm{a}}$ & $3,29 \pm 0,25^{\mathrm{a}}$ & $3,22 \pm 0,15^{\mathrm{a}}$ \\
II & $2,88 \pm 0,36^{\mathrm{a}}$ & $2,98 \pm 0,28^{\mathrm{a}}$ & $3,06 \pm 0,16^{\mathrm{a}}$ & $3,23 \pm 0,20^{\mathrm{a}}$ \\
III & $3,74 \pm 0,21^{\mathrm{b}}$ & $4,71 \pm 0,61^{\mathrm{b}}$ & $5,20 \pm 0,42^{\mathrm{b}}$ & $4,60 \pm 0,23^{\mathrm{b}}$ \\
IV & $4,01 \pm 0,28^{\mathrm{b}}$ & $4,78 \pm 0,17^{\mathrm{b}}$ & $5,38 \pm 0,20 \mathrm{~b}$ & $4,84 \pm 0,49 \mathrm{~b}$ \\
\hline DMS (5\%) & 0,33 & 0,45 & 0,33 & 0,36 \\
\hline DMS : Dif
\end{tabular}

DMS : Diferença mínima significativa.

Em todos os alongamentos foi possível mostrar diferenças significativas entre os grupos III e IV com os grupos I e II. Os grupos I e II não diferiram entre si, tendo resultados menores que os grupos III e IV. $(\mathrm{GI}=\mathrm{GII})<(\mathrm{GIII}=\mathrm{GIV})$.

\section{Discussão}

Muitos estudos sobre fios de sutura têm sido publicados, mas o que se observa é que há grande diversificação quanto ao método mais adequado para realizar os testes de resistência, isto é, se pela técnica de alça (HERRMANN, 1971; TERA e ABERG, 1977; CAMPBELL e BAILEY, 1992) ou pelo sistema USP (DUBIN e GREENBERG, 1981); a terminologia empregada (HOLMLUND, 1974; TERA e ABERG, 1976); formas de avaliação das propriedades dos nós (HERMANN, 1973; HOLMLUND, 1974; TERA e ABERG, 1976; TERA e ABERG, 1977; TRIMBOS, 1984; ROSIN e ROBINSON, 1989).

Tabela 5. Médias (x) e desvio-padrão (s) da resistência $(\mathrm{Kg})$, alongamento $(\mathrm{cm})$ e calibre $(\mathrm{mm})$ dos fios de náilon números 0 , 2-0, 3-0, 4-0 e 5-0.

\begin{tabular}{llllll}
\hline VARIÁVEIS & \multicolumn{5}{c}{ FIOS } \\
\cline { 2 - 6 } & 0 & $2-0$ & $3-0$ & $4-0$ & $5-0$ \\
\hline Resistência & $4,364 \pm 0,450$ & $3,545 \pm 0,290$ & $2,321 \pm 0,134$ & $1,522 \pm 0,084$ & $1,159 \pm 0,145$ \\
Alongamento & $14,730 \pm 0,323$ & $14,330 \pm 0,333$ & $14,710 \pm 0,633$ & $14,490 \pm 0,540$ & $13,830 \pm 0,419$ \\
Calibre & $0,363 \pm 0,012$ & $0,305 \pm 0,003$ & $0,262 \pm 0,001$ & $0,196 \pm 0,001$ & $0,152 \pm 0,002$ \\
\hline
\end{tabular}


Fio de Nailon e Linha de Pesca-Poliamida como Fios Cirúrgicos

Como um dos objetivos do trabalho foi estimar a resistência de tensão dos fios e não a de determinar a eficiência de nós, o teste empregado foi baseado no prescrito pela Farmacopéia dos Estados Unidos (USP), em que a resistência de tensão do material de sutura é determinada pelo deslocamento das extremidades de uma sutura amarrada com um nó de cirurgião $(2=1)$ ao redor de um tubo de borracha (apud HERRMANN, 1971; apud HOLMLUND, 1974; apud TERA e ABERG, 1976). Entretanto, por tratar-se de náilon, considerado um fio de difícil segurança do nó (BOOTHE, 1985), optou-se pelo nó de cirurgião sobre si mesmo, que é recomendado pela Farmacopéia Britânica (apud TERA e ABERG, 1976).

Geralmente para os mais diversos ensaios de tração de fios de sutura utiliza-se a máquina de Instron (HERRMANN, 1971; HOLMLUND, 1974; ROSIN e ROBINSON, 1989; CAMPBELL e BAILEY, 1992), entretanto, em função do seu alto custo, foi projetado e construído um extensômetro de resistência elétrica (Strain Gauge) por GUIMARÃES et al., (1998), no Centro de Manutenção de Equipamentos da Universidade Estadual Paulista, "Campus" de Botucatu (S.P.), com o qual foi possível efetuar as medidas de alongamento e da força de ruptura dos fios de linha de pesca, tornando, assim, viável a execução do presente trabalho.

Os calibres das "linhas de pesca" controle apresentaram algumas variações em relação ao citado pelo fornecedor. Por não se dispor da margem de erro fornecida pelo mesmo, não se pode afirmar que diferiram realmente.

$\mathrm{O}$ fato dos valores de resistência dos grupos controles da "linha de pesca" terem sido inferiores aos citados pelo fabricante, justifica-se, porque a força requerida para romper uma fibra não amarrada é superior à resistência de uma com nó (HOLMLUND, 1974).

Pelos resultados da análise estastística, verificouse que a esterilização pelo calor úmido exerceu um efeito adverso na resistência da "linha de pesca". DUBIN e GREENBERG (1981), autoclavando o Vetafil, observaram $0.5 \%$ de perda no ciclo. Por outro lado, não houve diferenças na resistência, no calibre e no alongamento da "linha de pesca" entre o primeiro e o segundo ciclo, o que vem de encontro à afirmação de SMEAK (1990) de que a autoclavagem é segura desde que não executada mais do que três vezes.

O menor comprimento da linha ocorrido após a autoclavagem, parece ter sido compensado por uma maior capacidade de alongamento verificado no teste de resistência e por um aumento de calibre. Um certo grau de alongamento (plasticidade) é desejável a um fio, para compensar, por exemplo, o aumento de volume de um tecido edemaciado, entretanto, quando em excesso pode permitir a formação de lacuna entre as margens de uma ferida. Desta forma, ao utilizar uma linha de pesca autoclavada deve ser levado em consideração que se está trabalhando com uma linha de resistência um pouco menor e com maior capacidade de alongamento.

Ao mesmo tempo que a autoclavagem tornou a linha mais maleável, ela também acentuou sua característica de memória, que é uma das particularidades do náilon (TURNER e McILWRAITH, 1985). Portanto, ao esterilizar a linha de pesca com este método, o ideal seria colocá-la de forma mais linear possível.

A relação tempo-temperatura (30 minutos a $120^{\circ} \mathrm{C}$ seguido por 10 minutos de secagem) empregado na esterilização das linhas foi $o$ mesmo e usado por DUBIN e GREENBERG (1981), embora de acordo com BERG e BLASS (1985) possa se obter um procedimento mínimo de segurança com 13 minutos de exposição em corrente saturada de vapor a $120^{\circ} \mathrm{C}$. Um dado a ser acrescentado é que com o procedimento de autoclavagem rotineiramente empregado na FMVZ -UNESP Botucatu (15 minutos à $140^{\circ} \mathrm{C}$ seguido por 15 minutos de secagem à $140^{\circ} \mathrm{C}$ ) foi observado, por meio de experimento piloto, uma alteração muito intensa da "linha de pesca" em termos de coloração, comprimento e manipulação; por isso o uso tempo-temperatura acima do utilizado neste experimento nos parece indesejável.

As linhas mantidas em pastilhas de formalina mantiveram na sua maioria suas características originais de resistência, comprimento, diâmetro (com exceção do fio 0,20$)$ e alongamento quando comparada ao grupo controle. Cabe lembrar que o formaldeído é considerado, em geral, como sendo irritante para pele e mucosa (BERG e BLASS, 1985).

No que se refere às reações teciduais produzidas pela "linha de pesca", RAHAL et al, (1997) realizaram um estudo comparativo com o fio de náilon cirúrgico, implantando segmentos de ambos sob a pele de ratos. O grau de reação tecidual levou os autores a concluir que a maior reação ocorreu com a linha de pesca mantida em formalina e a menor com o fio de náilon cirúrgico; as linhas de pesca autoclavadas uma e duas vezes se comportaram de forma semelhante e apresentaram uma reação intermediária.

Como não foi detectado crescimento bacteriano pela cultura, com os métodos de esterilização utilizados, considerou-se que ambos foram eficientes.

O calibre dos fios cirúrgicos avaliados, com exceção do número 4-0, estava dentro do padrão de variações citado por BELLEN e MAGALHÃES (1989). Quanto aos valores de resistência, não foi 
possível estabelecer uma comparação com os resultados de outro estudos, em virtude das grandes variações em procedimento de teste e também por não ter sido empregada a máquina de Instron. Seria interessante que medidas da performance mecânica dos fios de sutura fossem acrescentadas pelo fabricante às suas especificações, facilitando o acesso a essas informações, o que permitiria um uso mais consciente e objetivo dos mesmos.

Com os dados obtidos da resistência, calibre e alongamento foi possível estabelecer uma correlação das "linha de pesca" 0,$15 ; 0,20 ; 0,25$ e 0,30 com os fios cirúrgicos $5-0,4-0,3-0$ e 2-0 respectivamente.

Cabe lembrar que enquanto uma das grandes vantagens da "linha de pesca" em relação ao fio cirúrgico é o seu baixo custo (BELLENGER e MEEK, 1990), um dos seus grandes inconvenientes é a coloração. O fio cirúrgico, por ser de cor preta, facilita a sua visualização pelo cirurgião.

Pelos achados, podemos concluir que a "linha de pesca" apresenta características semelhantes ao fio de náilon cirúrgico, podendo ser mantida em pastilhas de formalina ou esterilizada em autoclave, lembrando que a autoclavagem altera algumas de suas propriedades físicas sem comprometer seu uso como fio cirúrgico.

\section{REFERÊNCIAS BIBLIOGRÁFICAS}

BELLEN, B.V.; MAGALHÃES, H.P. Fio cirúrgico. In: MAGALHÃES, H.P. Técnica cirúrgica e cirurgia experimental. São Paulo: Sarvier, Cap. 10. p. 93-98, 1989.

BELLENGER, C.R.; MEEK, M.A. The use of sutures in Australian Veterinary Practices. Austr. Vet. J., 67(3):81-86, 1990.

BERG, J.R.; BLASS, C.E. Sterilization. In: SLATTER, D.H. Textbook os small animal surgery. Philadelphia: Saunders, Cap. 20. p. 261-269, 1985.

BOOTHE, H.W. Suture materials and tissue adhesives. In: SLATTER, D.H. Textbook of small animal surgery. Philadelphia: Saunders, Cap. 27. p.334-344, 1985.

BUSSAB, W.O. Análise de variância e de regressão. Atual: São Paulo, 147p, 1986.

CAMPBELL, E.J. ; BAILEY, J.V. Mechanical properties of suture materials in vitro and after in vivo implantation in horses. Vet. Surgery, 21(5):55-361, 1992.
CAMPBELL, J.R.; MARKS, A. Suture materials and suturing techniques. In Practice, 7(3):72-75, 1985.

DUBIN, S.; GREENBERG, A. Effect of repeated sterilization on the breaking strength of synthetic polyfilament suture. J. Am. Vet. Med. Assoc., 178(11):1162, 1981.

GUIMARÃES, M.A.; LUCCHIARI, P.H.; FORTES, J.V.; BACILA,M. Otimização da medida da força de ruptura em processos de cicatrização. Arch. Vet. Scienc.3(1):123-128, 1998.

HERRMANN, J.B. Tensile strength and knot security of surgical suture materials. Am. Surg., 37(4):209-217, 1971.

HERRMANN, J. B. Changes in tensile strength and knot security of surgical sutures in vivo. Arch. Surg., 106:707-710, 1973.

HOLMLUND, D.E.W. Knot properties of surgical suture materials. Acta Chir. Scand., 140:335-362, 1974.

NARESSE, L.E.; MENDES, E.F.; CURI, P.R. et al. Aparelho para medida da força de ruptura das anastomoses intestinais. Rev. Hosp. Clín. Fac. Med. S. Paulo, 42:204-208, 1987.

OSTLE, B. Estadística aplicada. Mexico: Limusa-Wiley, 629p, 1973.

RAHAL, S.C.; ROCHA, N.S.; FIGUEIREDO, L.A; IAMAGUTI, P. Estudo comparativo das reações teciduais produzidas pela "linha de pesca" (poliamida) e o fio de náilon cirúrgico. Ciência Rural, Santa Maria, 28(1):89-93, 1997.

ROSIN, E.; ROBINSON, G.M. Knot security of suture materials. Vet. Surgery, 18(4):269-273, 1989.

SMEAK, D.D. Selection and use of currently avaiable suture materials. In: BOJRAB, M.J., BIRCHARD, S.J., TOMLINSON, J.C. Current techniques in small animal surgery. Philadelphia: Lea \& Febiger, Cap. 3, p. 34-39, 1990.

TERA, H.; ABERG, C. Tensile strengths of twelve types of knot employed in surgery using different suture materials. Acta Chir. Scand., 142(1):1-7, 1976.

TERA, H.; ABERG, C. Strength of knots in surgery in relation to type of knot, type of suture material and dimension of suture thread. Acta Chir. Scand., 143(2):75-83, 1977.

TRIMBOS, J.B. Security of various knots commonly used in surgical practice. Obstet. and Gynec., 64(2):274-280, 1984.

TURNER, A.S., McILWRAITH, C.W. Técnicas cirúrgicas em animais de grande porte. São Paulo: Roca. Materais de sutura: p. 67-77, 1985. 